\title{
Clinical indications and results after chest wall resection for recurrent mesothelioma
}

\author{
Bryan M. Burt, MD, ${ }^{\text {a }}$ Syed O. Ali, MD, ${ }^{\mathrm{b}}$ Marcelo C. DaSilva, MD, ${ }^{\mathrm{c}, \mathrm{d}}$ Beow Y. Yeap, ScD, ${ }^{\mathrm{d}, \mathrm{e}}$ \\ William G. Richards, PhD, ${ }^{\mathrm{c}, \mathrm{d}}$ Elizabeth H. Baldini, MD, MPH, ${ }^{\mathrm{c}, \mathrm{d}, \mathrm{f}}$ and David J. Sugarbaker, $\mathrm{MD}^{\mathrm{c}, \mathrm{d}}$
}

\begin{abstract}
Objective: The ipsilateral hemithorax is the most common site of recurrence after surgical resection for malignant pleural mesothelioma. Salvage treatment has generally been ineffective. We reviewed the outcomes after resection of isolated ipsilateral chest recurrence after cytoreductive surgery in patients with malignant pleural mesothelioma.
\end{abstract}

Methods: Patients with malignant pleural mesothelioma who underwent initial surgical resection at our institution from 1988 to 2011 and were subsequently treated for localized recurrence with an additional chest resection were identified and their data retrospectively reviewed.

Results: A total of 1142 patients underwent either extrapleural pneumonectomy $(n=794)$ or pleurectomy/ decortication $(\mathrm{n}=348)$. Of the patients who returned for follow-up, $47(4.1 \%)$ had chest wall recurrence amenable to resection. The location of recurrence was predominantly incisional $(49 \%)$ and/or costophrenic $(38 \%)$. The median time to recurrence after either extrapleural pneumonectomy or pleurectomy/ decortication was 16.1 months (range, 2.7-58.2). No 30-day mortality was found for chest wall resection, and the median length of stay in the hospital was 3 days (range, 0-12). The median overall survival duration after chest wall resection correlated positively with the time to recurrence (epithelial: median, 8.9, 17.2, and 35.8 months for a time to recurrence of $<12,12$ to $<24$, and $\geq 24$ months, respectively; biphasic: median, 2.7 and 15.9 months for a time to recurrence of $<10$ and $\geq 10$ months, respectively).

Conclusions: Chest wall resection is a safe and effective therapeutic option in the management of localized chest wall recurrence of malignant pleural mesothelioma. The time to recurrence appears to be predictive of the expected survival benefit in both epithelial and biphasic malignant pleural mesothelioma. (J Thorac Cardiovasc Surg 2013;146:1373-80)

Malignant pleural mesothelioma (MPM) is an aggressive malignancy with a poor prognosis and few effective treatment options. Without treatment, the median survival has been 6 to 9 months. Single modality therapy has provided a marginal survival benefit. ${ }^{1,2}$ Combination chemotherapy (pemetrexed with cisplatin vs cisplatin alone) has been shown to be superior to single agent chemotherapy. ${ }^{3}$ Surgery-based multimodality therapy, however, has become the mainstay of treatment of resectable MPM, and median survival rates of 14 to 28 months have

\footnotetext{
From the Department of Cardiothoracic Surgery, ${ }^{\text {a }}$ Stanford University Medical School, Stanford, Calif; Department of Cardiothoracic Surgery, ${ }^{b}$ Altru Health System, Grand Forks, ND; Division of Thoracic Surgery, ${ }^{\mathrm{c}}$ Brigham and Women's Hospital, Boston, Mass; Harvard Medical School, ${ }^{\mathrm{d}}$ Boston, Mass; Massachusetts General Hospital Cancer Center, ${ }^{\mathrm{e}}$ Massachusetts General Hospital, Boston, Mass; and Dana-Farber Cancer Institute, ${ }^{\mathrm{f}}$ Boston, Mass.

Disclosures: Authors have nothing to disclose with regard to commercial support. Read at the 92nd Annual Meeting of The American Association for Thoracic Surgery, San Francisco, California, April 28-May 2, 2012.

Received for publication May 1, 2012; revisions received May 24, 2013; accepted for publication July 3, 2013; available ahead of print Oct 10, 2013.

Address for reprints: David J. Sugarbaker, MD, Division of Thoracic Surgery, Brigham and Women's Hospital, Harvard Medical School, 75 Francis St, Boston, MA 02115 (E-mail: dsugarbaker@partners.org). $0022-5223 / \$ 36.00$

Copyright (C) 2013 Published by Elsevier Inc. on behalf of The American Association for Thoracic Surgery

http://dx.doi.org/10.1016/j.jtcvs.2013.07.012
}

been reported from various centers. ${ }^{4}$ Despite the progress seen with multimodality therapy, the high rate of recurrence after the initial resection has correlated with reduced survival. In a study investigating patterns of failure after trimodality therapy, the most common site of recurrence ( $35 \%$ overall and $67 \%$ of all recurrences) was the ipsilateral hemithorax. ${ }^{5,6}$ However, no effective strategies have been described in the published data regarding the treatment of isolated ipsilateral chest recurrence. Although systemic chemotherapy and radiotherapy remain the most common treatment approaches for recurrent disease, neither has offered a significant survival benefit. ${ }^{7,8}$ The role of surgical resection of ipsilateral chest wall recurrences has not been established in published studies.

The aim of the present study was to evaluate the morbidity, mortality, and survival rates associated with surgical resection of isolated ipsilateral chest wall recurrences after cytoreductive surgery for MPM.

\section{METHODS \\ Patients}

With approval from the institutional review board, we retrospectively reviewed the records of all patients in the International Mesothelioma Program Patient Data Registry at Brigham and Women's Hospital who had undergone cytoreductive surgery by either extrapleural pneumonectomy (EPP) or pleurectomy/decortication (PD) from January 1, 1988, through 


$$
\begin{aligned}
& \text { Abbreviations and Acronyms } \\
& \text { CT }=\text { computed tomography } \\
& \text { CWR }=\text { chest wall resection } \\
& \text { EPP }=\text { extrapleural pneumonectomy } \\
& \mathrm{MPM}=\text { malignant pleural mesothelioma } \\
& \mathrm{PD}=\text { pleurectomy/decortication } \\
& \mathrm{TTR}=\text { time to recurrence }
\end{aligned}
$$

January 31,2011 . We identified all patients who had subsequently undergone chest wall resection (CWR) for a solitary recurrence that was isolated to the ispilateral chest wall. We considered CWR to entail resection of at least $1 \mathrm{rib}$ and potentially included adjacent structures such as muscle and soft tissue, costal cartilages, the sternum, or diaphragm. The electronic and written medical records of these patients were reviewed to obtain clinicopathologic data. Survival was confirmed from the medical records, obituaries, and/or the Social Security Death Index. Our standard postoperative surveillance practice has been to monitor these patients with serial chest computed tomography (CT) scans, supplemented by positron emission tomography-CT for suspicious findings. A postoperative chest CT scan was arranged approximately 2 months after EPP or PD to establish a new baseline and rule out residual disease. The CT scans were then scheduled every 4 months for the next 2 years, after which the surveillance interval was increased. The time to recurrence (TTR) was defined as the interval after EPP or PD to the diagnosis of recurrence. The sites of recurrent disease were further characterized as (1) incisional (site of posterolateral thoracotomy), (2) costophrenic (lower chest wall or diaphragm), (3) paraspinal or sternal, or (4) superior chest (including the axilla).

\section{Statistical Analysis}

Statistical analysis was conducted using JMP statistical software, version 8.0 (SAS Institute, Cary, NC). For all statistical testing, we used a 2-sided significance level of $P=.05$. Descriptive statistics were collected. Where appropriate, the results are reported as the median and range for continuous variables. Between-group comparisons were made using the Mann-Whitney $U$ test for continuous variables and a chi-square test for categorical variables. Kaplan-Meier plots were used to estimate the survival functions for overall survival, defined as the point from the primary resection or first chest wall metastasis resection until death from any cause after surgery. The TTR was defined as the interval between an EPP or PD and the first sign of recurrence confirmed by imaging or on clinical examination. Differences in the survival outcome between patient groups were compared using the log-rank test.

\section{RESULTS}

Of the 1142 patients who underwent cytoreductive surgery by either EPP $(\mathrm{n}=794)$ or PD $(\mathrm{n}=348)$ during the study period, $47(4.1 \%)$ were identified who had subsequently developed ipsilateral local chest wall recurrence and underwent surgical resection. In these 47 patients, the recurrence was diagnosed by chest CT in 17 , positron emission tomography-CT in 16 , biopsy in 10 , palpation in 3 , and magnetic resonance imaging in 1 . Of the 47 patients, $16(34 \%)$ underwent repeat CWR for a second recurrence, and 3 underwent a third CWR for solitary recurrent disease. Thirteen of these 16 patients were in the epithelial group $(\mathrm{n}=32)$. The median age

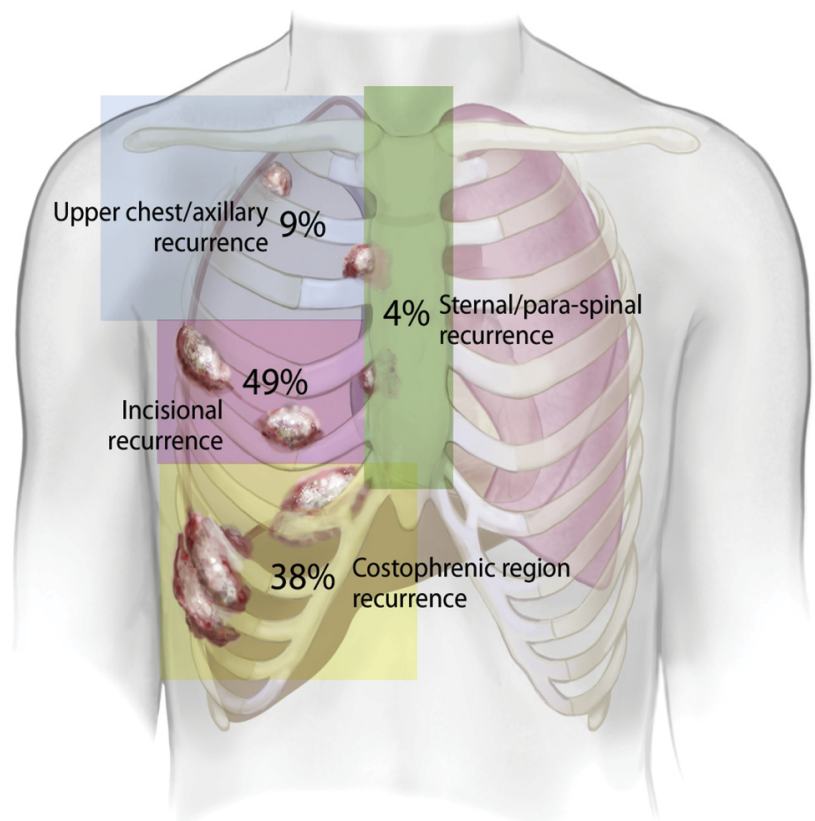

FIGURE 1. Location of isolated ipsilateral chest wall recurrence of malignant pleural mesothelioma after cytoreductive surgery.

was 61.9 years (range, 27.3-82.0). Most of the patients $(77 \%)$ were men. The presenting symptoms included a palpable mass in $77 \%$ and chest wall pain in $36 \%$. Most patients $(68 \%)$ had epithelial histology found by pathologic analysis of the primary resection specimen. The remaining $32 \%$ of patients had biphasic histology; no cases were found of sarcomatoid type MPM in our study. Ten patients $(21 \%)$ had $\mathrm{N} 2$ disease. Of the 47 patients, $32(68 \%)$ had initially been treated with EPP and 15 by PD (32\%). Also, $28 \%$ of the patients required mesh reconstruction of the chest wall defect after CWR, $63 \%$ were closed primarily, and $9 \%$ underwent muscle flap closure. The 30-day mortality was $0 \%$, and no complications such as wound infection, bleeding, or dehiscence were seen. The median length of stay in the hospital was 3 days (range, 0-12).

The distribution of chest wall recurrence resection sites is depicted in Figure 1. Of the recurrences, $49 \%$ were in the original thoracotomy incision, $38 \%$ were in the costophrenic region, and $9 \%$ were in the axilla or upper chest. One patient underwent a paraspinal resection, and one underwent sternal resection for recurrent disease. Resection in 2 patients included partial hepatectomy for en bloc removal of contiguous tumor as a part of the CWR (costophrenic region); 2 other patients underwent resection of disease at the ipsilateral diaphragmatic crura and mediastinum for contiguous disease at the costophrenic recurrence resection. Of the 16 patients who underwent a second CWR for a second chest wall recurrence, the recurrence site was at the previous site of CWR in 9 patients $(56 \%)$ and was at a new site on the chest wall in $7(44 \%)$. Among those patients 


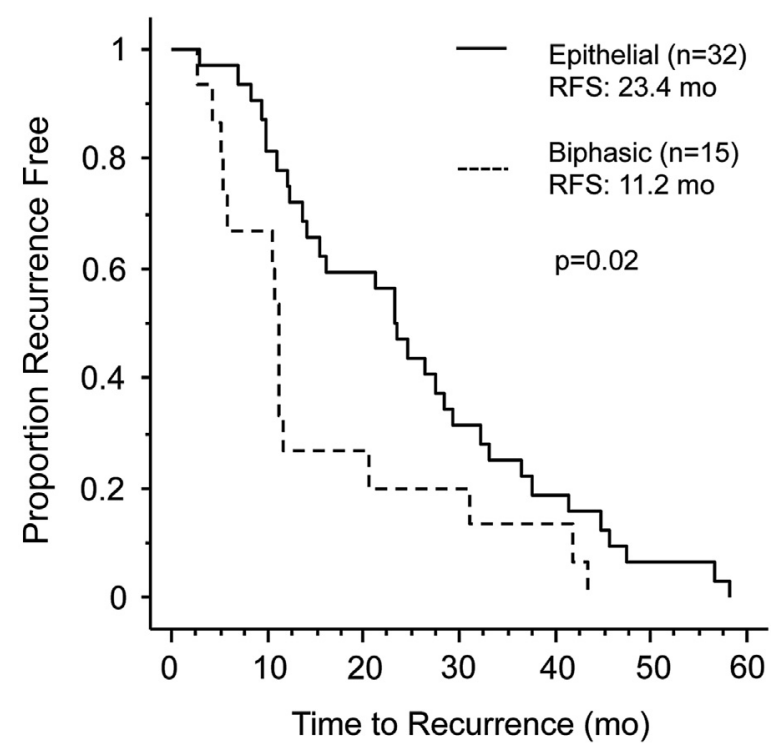

FIGURE 2. Interval to isolated, ipsilateral chest wall recurrence of malignant pleural mesothelioma after cytoreductive surgery. RFS, Recurrencefree survival.

undergoing a third CWR for a third chest wall recurrence, the disease recurred at the site of the CWR in 1 and was at a new site on the chest wall in 2 . Of the 15 patients with biphasic cell type at EPP or PD, 10 were found to have either epithelial $(n=8)$ or sarcomatoid $(n=2)$ histologic features at their CWR. In contrast, all 32 patients with epithelial histologic features on the initial EPP or PD retained an epithelial histologic type on chest wall recurrence.

As shown in Figure 2, the median TTR for the present cohort was 16.1 months (range, 2.7-58.2). For those with the epithelial type, it was 23.4 months (range, 2.7-58.2), significantly longer $(P=.022)$ than the TTR for those with the biphasic type at 11.2 months (range, 2.7-43.4). The median interval to CWR from primary EPP or PD was 22.4 months (range, 2.7-105.7). For patients with epithelial histologic features, it was 29 months (range, 2.7-105.7), and for those with biphasic histologic features, it was 11.7 months (range, 4.6-45.5). The overall median survival from the initial cytoreductive surgery for all patients undergoing CWR was 44.9 months (range, 3.8-130.5).

As shown in Figure 3, the survival from CWR was significantly longer $(P=.01)$ among patients with epithelial histologic features (median, 20.4 months; range, 1-73.1) than for those with mixed histology (median, 7.4 months; range, 1.3-34.7). Patients with epithelial type tumors were categorized into 3 subgroups according to the TTR: less than 12 months, 12 to less than 24 months, and 24 months or longer. Patients with biphasic type tumors were categorized into 2 subgroups (TTR $<10$ and TTR of $\geq 10$ months). The basis for these categorizations was the number of patients and the range of TTR in each group. Overall survival after CWR was positively related to the TTR for

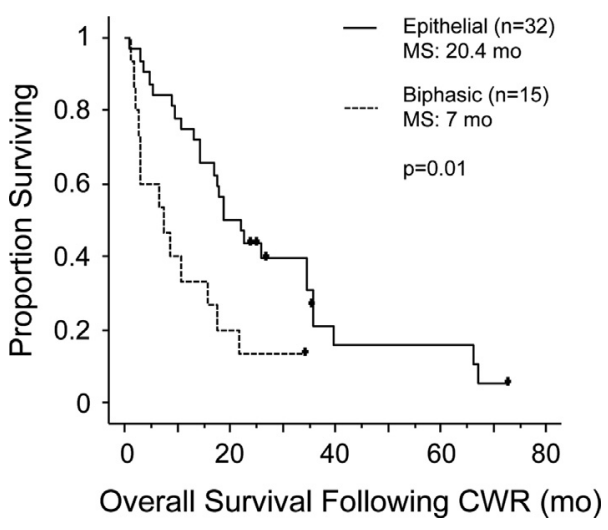

FIGURE 3. Overall survival after chest wall resection $(C W R)$ for isolated, ipsilateral chest wall recurrence of malignant pleural mesothelioma after cytoreductive surgery. MS, Median survival.

both epithelial (Figure 4, A) and biphasic (Figure 4, B) cell types. For those with the epithelial type, the median survival after CWR was 35.8 months when the TTR was 24 months or longer, 17.2 months when it was 12 to less than 24 months, and 8.9 months when it was less than 12 months $(P=.001)$. For those with the biphasic type, the median survival after CWR was 15.9 months when the TTR was 10 months or longer and was only 2.7 months when the TTR was less than 10 months $(P=.002)$. Early recurrence (within 6 months) was seen in 4 patients with epithelial and 2 patients with biphasic MPM.

With the exception of age for the epithelial cell type, none of the patient characteristics, tumor characteristics, or treatment parameters were significantly different among the patient subgroups for either epithelial or biphasic histologic types (Tables 1 and 2). For the epithelial type, the median age of the subgroups with a TTR of less than 12 months, 12 to less than 24 months, and 24 months or longer was 73, 62, and 51 years, respectively. The difference was statistically significant $(P=.03)$.

At their original EPP or PD, 3 patients were treated with neoadjuvant chemotherapy and 17 patients $(36 \%)$ received adjuvant chemotherapy. Also, 24 patients $(51 \%)$ were treated with heated intraoperative chemotherapy, and 20 $(43 \%)$ received adjuvant radiotherapy. At the diagnosis of recurrent disease, 23 patients $(49 \%)$ were treated with chemotherapy and $10(21 \%)$ with radiotherapy.

\section{DISCUSSION}

Recurrent disease in the ipsilateral chest is the most common site of first failure after surgery-based multimodality treatment of MPM. ${ }^{5}$ Early in the disease course, MPM tends to spread along the ipsilateral pleura. Metastatic dissemination to sites other than the abdomen or contralateral lung is uncommon but can occur in later phases of the disease or in patients who survive a long time after aggressive local therapy. With no treatment, most patients experience progressive local disease 


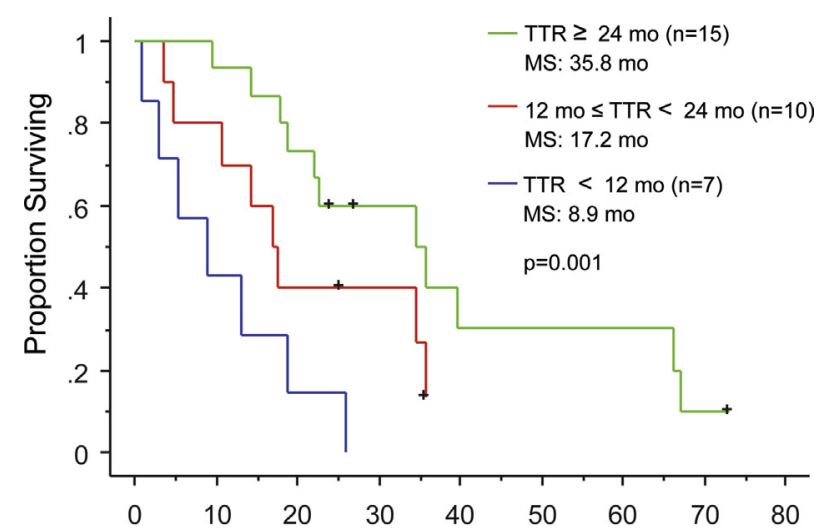

A

Overall Survival Following CWR (mo)

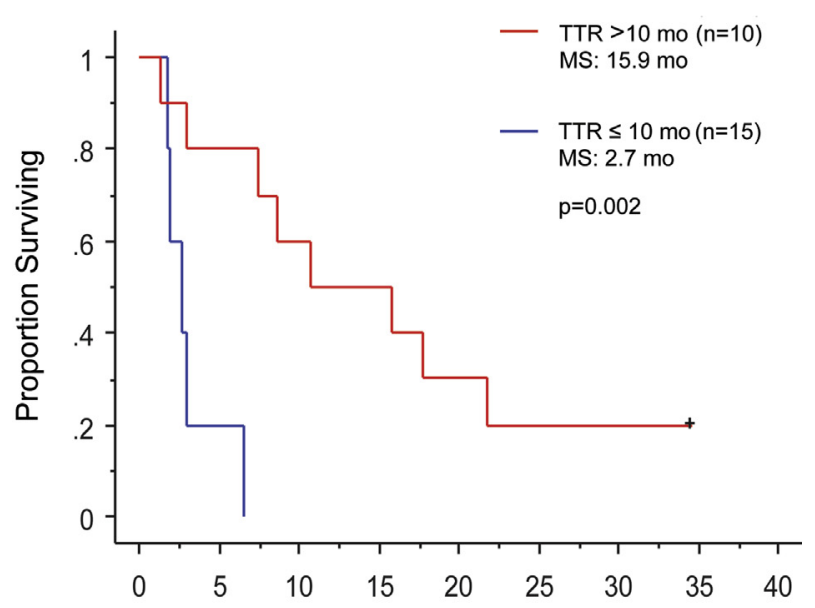

B

Overall Survival Following CWR (mo)

FIGURE 4. Overall survival after chest wall resection $(C W R)$ for an isolated, ipsilateral chest wall recurrence stratified by the time to recurrence (TTR) for A, epithelial and B, biphasic histologic tumors. $M S$, Median survival.

with invasion into adjacent tissues and subsequent death from complications arising from this process. ${ }^{2}$

Very little has been described in published studies with respect to salvage chest surgery for recurrent MPM. The only other study of this type was by Politi and Borzellino.? They reported 4 patients who had undergone CWR, 3 with retroperitoneal resection, and 1 with segmental lung resection. ${ }^{9}$ Although these investigators did not report extended survival after resection, the small sample size rendered any meaningful interpretation difficult.

The biology of epithelial and nonepithelial MPM tumors is different enough that we believe these tumors should be considered separately in any clinical or biologic analyses. The tumor histologic type is a well-established predictor of survival. ${ }^{10}$ This finding was also demonstrated in our study, in which the epithelial cell type was associated with greater overall survival. Furthermore, among patients with epithelial histologic features, younger age was associated with a longer interval to recurrence. This finding was also consistent with our earlier reported series on long-term survivors of MPM. ${ }^{11}$ From these results, the histologic type and patient age should be considered when evaluating the potential benefit of repeat resection in the setting of isolated metastasis.

We found that survival after repeat resection increases in an orderly manner with increasing TTR. This finding could help inform discussions of the risk/benefit ratios for second resection for patients diagnosed with an isolated recurrence. The histologic features of the original resection will provide additional refinement of the prognosis. For epithelial MPM, patients with a TTR in excess of 24 months had a median survival of an additional 35.8 months after CWR. In contrast, for patients with biphasic MPM, which tended to recur early in the postoperative period after primary EPP or PD, only an additional 2.7 months survival was achieved after CWR if the TTR was less than 10 months. Thus, this latter group of patients might be better served by palliation or salvage modalities such as chemotherapy or radiotherapy, or both. ${ }^{7,8}$ For example, on occasion, we will use stereotactic ablative radiotherapy to chest wall metastases in patients who are not candidates for CWR, with good anecdotal results.

At EPP or PD, the tumor cells can also disseminate into the operative field or contaminate the incision. In many cases, it is plausible that this was the etiology of recurrent disease. We found that the most common site of ipsilateral chest wall recurrence was along the original thoracotomy incision (49\%), followed by the costophrenic sulcus (38\%, Figure 1). Recurrence along the thoracotomy incision most likely results from tumor seeding, and 1 potential method for addressing this is by modifications in the surgical technique. Our practice has included minimizing dissection planes at the thoracotomy incision site (ie, minimize the blunt dissection often performed to identify the correct rib space), performing a chemical wash of the thoracotomy incision with hydrogen peroxide, and performing a distilled water and saline lavage with a pulsed lavage irrigator. Radiotherapy has also been used as a prophylactic treatment to reduce the incidence of recurrence in incisional sites; however, the reported efficacy for this has been mixed. ${ }^{12-14}$

It is often difficult to obtain complete surgical clearance of tumor in the costophrenic sulcus, and, as such, it is not surprising that this location is another common site of relapse. Furthermore, for patients who undergo radiotherapy as a part of their trimodal therapy, this has been a common site of local recurrence. ${ }^{15-17}$ Two explanations for costophrenic recurrence after radiotherapy include that, first, the treatment field borders sometimes do not extend as inferiorly as they should (at least to the bottom of L2), and, second, for technical reasons, the costophrenic sulcus is a common area of dose inhomogeneity. Moreover, it is difficult to escalate the radiation dose to the costophrenic 
TABLE 1. Demographics and clinical and pathologic characteristics of patients with epithelial cell type undergoing chest wall resection for local mesothelioma recurrence $(n=32)$

\begin{tabular}{|c|c|c|c|c|c|}
\hline Variable & $\begin{array}{c}\text { All epithelial } \\
\text { cell type patients }\end{array}$ & $\begin{array}{c}\text { Epithelial } \leq 12 \text {-mo } \\
\text { TTR (group 1) }\end{array}$ & $\begin{array}{c}\text { Epithelial 12-24 mo } \\
\text { TTR (group 2) }\end{array}$ & $\begin{array}{c}\text { Epithelial } \geq 24-\text { mo } \\
\text { TTR (group 3) }\end{array}$ & $P$ value \\
\hline Patients (n) & 32 & 7 (21.9) & $10(31.3)$ & $15(46.9)$ & \\
\hline Median age (y) & 64 & 73 & 62 & 51 & .03 \\
\hline Gender & & & & & .7 \\
\hline Female & $10(31)$ & $3(42.8)$ & $3(30)$ & $4(26.7)$ & \\
\hline Male & $22(69)$ & $4(57.14)$ & $7(70)$ & $11(73.3)$ & \\
\hline Laterality & & & & & .2 \\
\hline Right & $19(59)$ & $3(42.9)$ & $8(80)$ & $8(53.3)$ & \\
\hline Left & $13(41)$ & $4(57.1)$ & $2(10)$ & $7(46.7)$ & \\
\hline Pain* & & & & & .3 \\
\hline No & $21(66)$ & $3(42.9)$ & $8(80)$ & $10(66.7)$ & \\
\hline Yes & $11(34)$ & $4(57.1)$ & $2(20)$ & $5(33.3)$ & \\
\hline Palpable mass* & & & & & .2 \\
\hline No & $8(25)$ & 0 & $4(40)$ & $4(26.7)$ & \\
\hline Yes & $24(75)$ & $7(100)$ & $6(60)$ & $11(73.3)$ & \\
\hline Initial surgical approach & & & & & .5 \\
\hline $\mathrm{PD}$ & $12(37)$ & $3(42.9)$ & $5(50)$ & $4(26.7)$ & \\
\hline EPP & $20(63)$ & $4(57.1)$ & $5(50)$ & $11(73.3)$ & \\
\hline $\mathrm{N} 2$ disease & & & & & .3 \\
\hline No & $24(75)$ & $4(57.1)$ & $7(70)$ & $13(86.7)$ & \\
\hline Yes & $8(25)$ & $3(42.9)$ & $3(30)$ & $2(13.3)$ & \\
\hline Reconstruction with mesh* & & & & & .06 \\
\hline No & $23(72)$ & $7(100)$ & $8(80)$ & $8(53.3)$ & \\
\hline Yes & $9(28)$ & 0 & $2(20)$ & $7(46.7)$ & \\
\hline Second CWR & & & & & 1.0 \\
\hline No & $19(59)$ & $4(57.1)$ & $6(60)$ & $9(60)$ & \\
\hline Yes & $13(41)$ & $3(42.9)$ & $4(40)$ & $6(40)$ & \\
\hline
\end{tabular}

Data presented as n (\%), unless otherwise noted. TTR, Time to recurrence; $P D$, pleurectomy/decortication; $E P P$, extrapleural pneumonectomy; $C W R$, chest wall resection. $*$ At the time of CWR.

sulci because of the radiation sensitivity of the underlying kidneys and liver (for right-sided cases) and stomach (for left-sided cases). Of the 47 patients in our cohort, 18 (38\%) underwent CWR for a costophrenic angle recurrence. Of these 18 patients, 7 (39\%) received postoperative radiotherapy. Finally, the lower chest wall is a common site to enter the chest when obtaining a pleural biopsy to establish a diagnosis. Tumor dissemination occurs in up to $40 \%$ of thoracoscopy sites and up to $10.4 \%$ of needle biopsy tracts. ${ }^{12-14,18}$ We have, therefore, implemented a standard practice of excising all thoracoscopy and needle biopsy sites, when feasible, at EPP and PD.

Of the recurrences in the present series, $87 \%$ were in the lower chest (costophrenic and incisional combined) and only $9 \%$ were in the apex or axilla (Figure 1). This pattern of recurrence is consistent with the natural history of MPM and its distribution in the pleural space, such as can be seen in patients at their EPP or PD. Among the patients in the present cohort who underwent resection for a costophrenic recurrence, some had disease in the lower chest wall that had directly invaded the retroperitoneum and/or abdomen. Two patients in this group underwent partial hepatectomy for contiguous disease, and another two had contiguous ipsilateral diaphragmatic crural and/or mediastinal involvement, which was also resected at their CWR. When resecting recurrences in patients with contiguous disease, our goal has been to remove all involved structures en bloc in an attempt to perform a proper oncologic resection.

For the patients who underwent a second CWR for isolated recurrence, a longer overall median survival was noted. Multiple serial resections for locally recurrent MPM can be associated with prolonged survival, similar to that seen after repeated metastasectomies performed for pulmonary metastases in other diseases. ${ }^{2,19,20}$

Performing a second surgery on patients with MPM allowed us to compare the histologic cell type at the first surgery with that at the CWR (second surgery). We noted an interesting trend in that more than one half of the patients diagnosed with a biphasic cell type at the initial surgery were found to have a predominantly epithelial cell type $(53 \%)$ at their second surgery. This might have resulted from the selection of the epithelial component as retained viable microscopic disease after surgery and/or adjuvant modalities such chemoradiotherapy. Alternatively, biphasic MPM might transition to predominantly the epithelial or sarcomatoid type in certain cases of recurrent disease, 
TABLE 2. Demographics and clinical and pathologic characteristics of patients with biphasic cell type undergoing chest wall resection for local mesothelioma recurrence $(n=15)$

\begin{tabular}{|c|c|c|c|c|}
\hline Variable & $\begin{array}{l}\text { All biphasic } \\
\text { cell type } \\
\text { patients }\end{array}$ & $\begin{array}{c}\text { Biphasic } \\
\text { cell type, } \\
\text { 0-10 mo } \\
\text { TTR (group 1) }\end{array}$ & $\begin{array}{c}\begin{array}{c}\text { Biphasic } \\
\text { cell type }\end{array} \\
>10 \text { mo } \\
\text { TTR (group 2) }\end{array}$ & $\begin{array}{c}P \\
\text { value }\end{array}$ \\
\hline Patients & 15 & $5(33.3)$ & $10(66.6)$ & \\
\hline Median age (y) & 62 & 58 & 64 & .59 \\
\hline Gender & & & & .1 \\
\hline Female & $1(7)$ & $1(20)$ & 0 & \\
\hline Male & $14(93)$ & $4(80)$ & $10(100)$ & \\
\hline Laterality & & & & .7 \\
\hline Right & $11(73)$ & $4(80)$ & $7(70)$ & \\
\hline Left & $4(41)$ & $1(20)$ & $3(30)$ & \\
\hline Pain* & & & & .3 \\
\hline No & $9(60)$ & $4(80)$ & $5(50)$ & \\
\hline Yes & $6(40)$ & $1(20)$ & $5(50)$ & \\
\hline Palpable mass* & & & & .3 \\
\hline No & $3(20)$ & 0 & $3(30)$ & \\
\hline Yes & $12(80)$ & $5(100)$ & $7(70)$ & \\
\hline Surgical approach & & & & 1.0 \\
\hline $\mathrm{PD}$ & $3(20)$ & $1(20)$ & $2(20)$ & \\
\hline EPP & $12(80)$ & $4(80)$ & $8(80)$ & \\
\hline $\mathrm{N} 2$ disease & & & & .3 \\
\hline No & $13(87)$ & $5(100)$ & $8(80)$ & \\
\hline Yes & $2(13)$ & 0 & $2(20)$ & \\
\hline $\begin{array}{l}\text { Reconstruction } \\
\text { with mesh* }\end{array}$ & & & & .7 \\
\hline No & $11(73)$ & $4(80)$ & $7(70)$ & \\
\hline Yes & $4(27)$ & $1(20)$ & $3(30)$ & \\
\hline Second CWR & & & & 1.0 \\
\hline No & $12(80)$ & $4(80)$ & $8(80)$ & \\
\hline Yes & $3(20)$ & $1(20)$ & $2(20)$ & \\
\hline
\end{tabular}

Data presented as $\mathrm{n}(\%)$, unless otherwise noted. TTR, Time to recurrence $P D$, pleurectomy/decortication; $E P P$, extrapleural pneumonectomy; $C W R$, chest wall resection. *At the time of CWR.

when observed over a period. It might be that the patients with transition to an epithelial type are more likely to present with an isolated recurrence and those with transition to a sarcomatoid type are more likely to develop multiple recurrences. Additional studies are needed to investigate this phenomenon.

The main limitations of our study were its retrospective nature and the highly selected patient cohort. We only reviewed patients who returned for follow-up to our clinic and underwent CWR for localized and solitary recurrence. The follow-up of all 1142 patients undergoing EPP or PD was not sufficient to provide an accurate depiction of the incidence of chest wall recurrence that is amenable to CWR. Thus, the true percentage of patients who might have developed diffuse and multiple chest wall metastases could not be accurately derived. Another potential drawback of our study was that a large number of patients received adjuvant therapy, and some were treated with chemotherapy and/or radiotherapy for recurrent disease before repeat resection. This wide variety of adjunct therapeutic modalities likely represents the evolution of our approach to patients with MPM, and the evolution of our investigational protocols during the 23 -year study period. It would be difficult to ascertain the role these treatments might have played in addition to the CWR in extending patient survival after CWR. For reference, our current treatment approach includes preoperative cervical mediastinoscopy for all patients with MPM, and patients with pathologically determined $\mathrm{N} 2$ disease are recommended to undergo neoadjuvant chemotherapy. At our institution, patients undergoing EPP or PD are usually offered heated intraoperative chemotherapy. Despite these limitations, we believe our study had a number of strengths, including a relatively large sample size with localized chest wall recurrence and treatment at an institution highly experienced in treating patients with MPM.

In conclusion, our results have indicated that for select patients with isolated chest wall recurrence of MPM, salvage CWR (performed with an intent to cure) is an effective strategy associated with favorable survival rates at the expense of minimal morbidity. Patients with a prolonged TTR will benefit the most. It is appropriate to consider curative CWR as standalone therapy or in conjunction with other adjuvant modalities in the management of localized ipsilateral chest recurrence for patients with a good performance status and for whom the anticipated surgical morbidity is minimal.

\section{References}

1. Antman KH. Clinical presentation and natural history of benign and malignant mesothelioma. Semin Oncol. 1981;8:313-20.

2. Van Marck E. Pathology of malignant mesothelioma. Lung Cancer. 2004; 45(suppl 1):S35-6.

3. Vogelzang NJ, Rusthoven JJ, Symanowski J, Denham C, Kaukel E, Ruffie P, et al. Phase III study of pemetrexed in combination with cisplatin versus cisplatin alone in patients with malignant pleural mesothelioma. J Clin Oncol. 2003;21: 2636-44.

4. Zauderer MG, Krug LM. The evolution of multimodality therapy for malignant pleural mesothelioma. Curr Treat Options Oncol. 2011;12:163-72.

5. Baldini EH, Recht A, Strauss GM, DeCamp MM Jr, Swanson SJ, Liptay MJ, et al. Patterns of failure after trimodality therapy for malignant pleural mesothelioma. Ann Thorac Surg. 1997;63:334-8.

6. Janne PA, Baldini EH. Patterns of failure following surgical resection for malignant pleural mesothelioma. Thorac Surg Clin. 2004;14:567-73.

7. Price A. What is the role of radiotherapy in malignant pleural mesothelioma Oncologist. 2011;16:359-65.

8. Ceresoli GL, Zucali PA, Gianoncelli L, Lorenzi E, Santoro A. Second-line treatment for malignant pleura mesothelioma. Cancer Treat Rev. 2010;36:24-32.

9. Politi L, Borzellino G. Second surgery for recurrence of malignant pleural mesothelioma after extrapleural pneumonectomy. Ann Thorac Surg. 2010;89: 207-10.

10. Sugarbaker DJ, Flores RM, Jaklitsch MT, Richards WG, Strauss GM, Corson JM, et al. Resection margins, extrapleural nodal status, and cell type determine postoperative long-term survival in trimodality therapy of malignant pleural mesothelioma: results in 183 patients. J Thorac Cardiovasc Surg. 1999;117:54-63.

11. Sugarbaker DJ, Wolf AS, Chirieac LR, Godleski JJ, Tilleman TR, Jaklitsch MT, et al. Clinical and pathological features of three-year survivors of malignant pleural mesothelioma following extrapleural pneumonectomy. Eur J Cardiothorac Surg. 2011;40:298-303.

12. Boutin C, Rey F, Viallat JR. Prevention of malignant seeding after invasive diagnostic procedures in patients with pleural mesothelioma: a randomized trial of local radiotherapy. Chest. 1995;108:754-8. 
13. Bydder S, Phillips M, Joseph DJ, Cameron F, Spry NA, DeMelker Y, et al. A randomised trial of single-dose radiotherapy to prevent procedure tract metastasis by malignant mesothelioma. Br J Cancer. 2004;91:9-10.

14. O'Rourke N, Garcia JC, Paul J, Lawless C, McMenemin R, Hill J. A randomised controlled trial of intervention site radiotherapy in malignant pleural mesothelioma. Radiother Oncol. 2007;84:18-22

15. Allen AM, Den R, Wong JS, Zurakowski D, Soto R, Jänne PA, et al. Influence of radiotherapy technique and dose on patterns of failure for mesothelioma patients after extrapleural pneumonectomy. Int J Radiat Oncol Biol Phys. 2007;68: 1366-74.

16. Gupta V, Krug LM, Laser B, Hudka K, Flores R, Rusch VW, et al. Patterns of local and nodal failure in malignant pleural mesothelioma after extrapleural pneumonectomy and photon-electron radiotherapy. J Thorac Oncol. 2009;4: 746-50.

17. Yajnik S, Rosenzweig KE, Mychalczak B, Krug L, Flores R, Hong L, et al. Hemithoracic radiation after extrapleural pneumonectomy for malignant pleural mesothelioma. Int J Radiat Oncol Biol Phys. 2003;56:1319-26.

18. Metintas M, Ak G, Parspour S, Yildirim H, Erginel S, Alatas F, et al. Local recurrence of tumor at sites of intervention in malignant pleural mesothelioma. Lung Cancer. 2008;61:255-61.

19. Pastorino U, Buyse M, Friedel G, Ginsberg RJ, Girard P, Goldstraw P, et al. Long-term results of lung metastasectomy: prognostic analyses based on 5206 cases. Cardiovasc Surg. 1997;113:37-49.

20. Burt BM, Ocejo S, Mery CM, Dasilva M, Bueno R, Sugarbaker DJ, Jaklitsch MT. Repeated and aggressive pulmonary resections for leiomyosarcoma metastases extends survival. Ann Thorac Surg. 2011;92:1202-7.

\section{Discussion}

Dr Walter Weder (Zurich, Switzerland). I would like to congratulate Dr Ali and the group from Boston for their clinically relevant contribution to surgical treatment of local recurrences by chest wall resection in patients with malignant pleural mesothelioma. I received the report in time for a critical review.

Dr Ali and colleagues identified 47 patients with local recurrence of malignant pleural mesothelioma who were amenable for resection of 1142 patients who had undergone radical resection either by EPP (794 patients) or PD (348 patients). This accounts for $4.1 \%$ of all operated cases. Taking into consideration that the reported local recurrence rate in the ipsilateral chest after EPP is around $35 \%$ to $40 \%$ and probably even higher after PD, only around $12 \%$ of all patients with local recurrence were selected for surgical treatment. In part, this relatively small number was because patient follow-up was done outside your service. Nevertheless, it seems that you have been very selective.

This brings me to my first question. How did you exactly select your patients? Was it based primarily on CT scan, looking for a localized resectable bulk, or was the clinical picture more important-nonfixed tumor, pain? Is there an upper tumor size or tumor extension? How important are the positron emission tomography findings, which clearly show local extension more precisely? Does it matter if the planned resection will be radical or not? Is patient selection for chest wall resection different for patients after EPP than after PD?

Dr Ali. The way we select our patients is we follow them up in our postoperative clinic and we obtain routine CT scans. The first $\mathrm{CT}$ scan is done at 6 to 8 weeks and serves as a baseline. Thereafter, we repeat the CT scans every 4 months. Usually on imaging or on the clinical examination, if there is a suspicion of recurrent disease, we often obtain a positron emission tomography-CT scan. This is how we identify recurrent disease.

As far as who is a good candidate for chest wall resection, this is basically solitary or isolated disease. As we saw in this breakdown, about one half of them were at the incisional site, and $38 \%$ were at the costophrenic angle. As you can imagine, the incisional site is most likely because of tumor seeding, and perhaps the disease at the costophrenic angle was secondary to this being a difficult area to achieve macroscopic clearance at. The patients are selected primarily on the criteria based on the question, "Can we achieve complete resection and return them to their decreased tumor burden?" It is like resetting the tumor burden. If we believe the patient has more than 1 thoracic recurrence (ie, it is not solitary disease), we would offer them surgery. However, this study included only patients with solitary recurrent disease. If extrathoracic diseases present, as well as chest wall recurrence, generally speaking, they would not be offered chest wall resection.

As to your last point, the extent of resection, for patients who had disease in the costophrenic sulcus, often it extends contiguously into the retroperitoneum, and we had at least 3 patients in this study who ended up undergoing an en bloc retroperitoneal mass resection. In 2 patients, the disease extended toward the mediastinum, and the remnant diaphragmatic crura was resected en bloc with the chest wall resection.

Dr Weder. In your study, you showed nicely that early recurrence is a poor prognostic sign, an observation also made in other clinical questions with malignancies, such as surgical treatment of metastasis. My second question regards the indication for surgery in relation to the onset of the recurrence. In which cases do you not recommend surgery because of the expected aggressive biologic behavior of the tumor? Is there a recommended cutoff time?

Dr Ali. That is a very good question. As you know, in mesothelioma, the primary determinant of survival is the cell type, or, in other words, the tumor biology. The epithelial cell type tends to have a longer survival. In this study, patients who had their first recurrence after primary macroscopic resection, when the TTR (or time to recurrence) was more than 24 months, their median survival was 35.9 months. Now, in the same study, we had patients with biphasic-type disease whose TTR was less than 10 months, and their median survival after chest wall resection was a mere 2.7 months. So clearly, the tumor biology is an important determinant. I think this allows us to determine the criteria according to the TTR as to which patients we should offer a second surgery to.

Dr Shrager. I think his question was what criteria would you propose.

Dr Ali. I think for the biphasic type, when they recur early, you have to consider other therapies, such as radiotherapy or second-line, third-line chemotherapy, especially when they recur within less than 10 months. Now, this study has 47 patients who were highly selected. So I think we can use this as a guideline in the future, especially for the biphasic type.

Dr Weder. But those with the epithelial type, those with early recurrence had a very poor prognosis. So, I would not make the cutoff exactly just for the mixed type. I think also the epithelial type can behave very aggressively when it occurs early. So my last question is, what about local recurrence after chest wall resection, especially in these aggressive subtypes, did you see problems in this regard?

Dr Ali. Yes. One third of these patients ended up undergoing a second chest wall resection. We believe if there is repeat recurrence and if we can resect it and return the patients back to 
their previous tumor burden, that is, reset their homeostasis, so to speak, then we would offer them surgery. The median survival for patients who had undergone 2 or more resections was actually 59 months. So, in a way, in this highly selected subset of patients, repeat recurrence was not an impediment to repeat resection.

Dr Weder. Also, for the one who had occurred early, the very aggressive one, you have not seen recurrence there?

Dr Ali. No. Those who recurred early, no, we did not.

Dr Weder. Thank you very much.

Dr Robert B. Cameron (Los Angeles, Calif). I want to congratulate you on an obviously impressive series. I have a lot of questions, but I will limit them to 2 .

First is regarding the 25-year period that you are reporting on. I am just curious, because a number of other things have been developed during that 25 years, including stereotactic body radiotherapy, radiofrequency ablation, and other localized treatments that are short of surgery. Can you comment on the use of those in your series? Did you use any of them, and did you find that they were less effective? Also, in light of that, does any difference exist in morbidity in performing chest wall resection vs performing stereotactic body radiotherapy?

Dr Ali. That is a very good question. These are cases from our database, and the selection criterion was to include patients who had undergone chest wall resection for solitary disease. So in this study, we could not compare other modalities based on that. Having said that, for recurrent disease at the costophrenic sulcus, for example, radiotherapy often has its limits of how much radiation you can give. There are radiosensitive organs at the costophrenic sulcus such as the stomach on the left and liver on the right, and, second, often patients have reached their maximum radiation limit after multimodality therapy for mesothelioma. In patients who have undergone PD with their lung still in the ipsilateral chest, radiotherapy can be associated with side effects such as radiation pneumonitis. So, clearly, there are certain side limitations one must keep in mind. I cannot comment on which technique is superior.
Dr Cameron. I would like to take the opportunity, then, to invite you to the ethereal world of the "POD." We have an abstract that is in the POD downstairs, wherever that is, that reports on 86 lesions that were treated with cryoablation of local recurrence after pleurectomy, and we had a success rate of permanent control of those lesions $98 \%$ of the time without any surgery. So, I would just invite you to review that because I think that that will basically obviate the need for any chest wall resection, and a lot of those were chest wall recurrences that were treated successfully up to $6 \mathrm{~cm}$.

I have to ask 1 last question, which is kind of the elephant in the room. Whenever you talk about mesothelioma, everybody says, well, we have no randomized trials and all that sort of thing, but you just reported on almost 800 EPPs. With the mounting evidence from a number of different groups, including the Mesothelioma and Radical Surgery (MARS) trial, that EPP might not have any benefit in this disease, are we going to be hearing in the near future about your randomized prospective clinical trial of EPP and whether it works or not?

Dr Ali. I think in surgery for mesothelioma, there could be some debate, but clearly the results from our institution show that excellent survival can achieved using a multimodality, surgery-based approach, and I think what we are showing here today is that a second surgery for select cases should also be considered.

Dr Antoon Lerut (Leuven, Belgium). Thank you for an excellent presentation.

I would like to come back to the 1 of 3 patients who underwent a second chest wall resection. You mentioned that the overall median survival was 59 months from the date of primary surgery, but what was the median survival from the date of the second chest wall resection? That perhaps might give an idea about the aggressiveness of the second recurrence.

Dr Ali. In those 16 patients, their median survival after the second resection was 14.5 months. 